\title{
Biped Robot: Balance Center of Gravity on Uneven or Smooth Terrain
}

\author{
R. Hariharan, CM Meenakshi, Durai Raj V P
}

\begin{abstract}
We present a framework whereby the human movement is repeated in order to give financially savvy strategies to move the biped robots in to the modern age which is as yet delicate with explained and synergistic robots by utilizing limit of 7 hub opportunity or movement and wanderer robots with less spryness over terrains of war to mirror human developments in fight zones. This drove us to gadget a biped robot for better strolling and adjusting. Its mechanical structure including the joint setup and particular, the structure of knee joint, the speed decrease system in the servo engine by programming, and the mechanical cross supporting are utilized are depicted in detail. A particular control framework ATmega2560 on the Mega 2560 (Arduino Board) for biped that is a sequential and disseminated system and comprises of a microcontroller, bootloader, servo information and yield pins, sensor info and yield pins, TWI/I2C framework. With the created biped robot, biped strolling and one-leg adjusting and weight moving while at the same time strolling for better entryway movement in 5000[ms] are actualized as fundamental and confirmation tests for quick strolling and adjusting.
\end{abstract}

Keywords : Human Gait movement, Biped, Servo motor, Robotics

\section{INTRODUCTION}

In this examination, we planned a novel biped robot with various purposes. Potential benefits of such a biped structure are as per the following. Initial, a superior structure can be utilized in prosthetic biped motion and will give the ability to do genuine work, mirroring the development capacity of a genuine human legs and subsequently improving the expectations for everyday comforts or potentially solace of individuals who have lost their legs for an assortment of reasons from midsection. Second, it very well may be utilized in safeguard with a legitimate plan to chest area it tends to be at that point exposed to a brutal circumstances[1],[3],[5]. The most significant necessity for the solid and sensible plan of a biped robot is to have a straightforward control framework and easy to use tasks with easy to use interface. The present propelled business bipeds are for the most part constrained by versatile processor, for example, Intel Atom processor numerous accelerometer and advanced gyrator. The sign are sent by utilizing weight sensors or material sensor that see power related with the movement and changes over and sends

Revised Manuscript Received on August 22, 2019.

R. Hariharan, Department of Mechanical Engineering, Bharath Institute of Higher Education and Research, Chennai, Tamilnadu, India. Email: mech.hariharan17@gmail.com

CM Meenakshi, Department of Mechanical Engineering, Bharath Institute of Higher Education and Research, Chennai, Tamilnadu, India. Email: cmmeenakshidhanush@gmail.com

Durai Raj V P, Department of Mechanical Engineering, Bharath Institute of Higher Education and Research, Chennai, Tamilnadu, India. Email: durairaj_vp@yahoo.com them into electrical heartbeats. The controller in the biped robot translates a few channels of PWM procured from different sensors or accelerometer and spinner, and therefore it drives the fitting actuators to play out the proposed movement. Investigations have demonstrated that however various oppressed burden under could control condition on the biped still dispenses with mistake for utilizing in numerous situations preparing and experimentation will be required, the principle deficiency of this servo driven methodology is that most degrees of opportunity (DOF) can't be accomplished, as they have to progressively number of equipped engines to perform fitting turn in hip and legs. Because of the gigantic necessity power source is there to make biped convenient a Li-MH battery pack is utilized, up to this point just Li-Ion batteries have been settled upon as an adequate arrangement. So as to make models convenient. We have appeared with perfect measure of exertion it can change to other battery packs as well[2],[4],[6].

\section{FABRICATED PARTS AND WORKING}

\section{A. The Accelerometer Module}

The module could perceive contrast in slight tilts in each of the three tomahawks. It gets varieties The ADXL335 utilizes a solitary structure for detecting the $\mathrm{X}, \mathrm{Y}$, and $\mathrm{Z}$ tomahawks. Subsequently, the three tomahawks' sense bearings are exceptionally symmetrical and have minimal cross-pivot affectability. Mechanical misalignment of the sensor pass on to the bundle is the central wellspring of cross-pivot affectability. Mechanical misalignment can, obviously, be adjusted out at the framework level. In ADXL335 there is no quantization blunder or non-monotonic conduct, and temperature hysteresis is exceptionally low, this is the explanation we utilize this accelerometer. Associated with the Arduino Mega2560 board. The varieties are gotten as contribution to the microcontroller. By utilizing the program composed
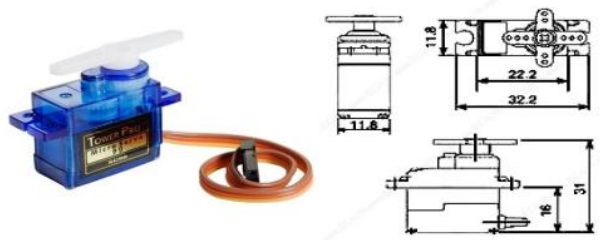

Figure - 1 Servo Motor

Minor and lightweight with high yield control. Servo can turn around 180 degrees (90 toward every path), and works simply 
like the standard sorts yet littler. You can utilize any servo code, equipment or library to control these servos. Useful for fledglings who need to make stuff move without structure an engine controller with input and apparatus box, particularly since it will fit in little puts. It accompanies a 3 horns (arms) and equipment[7],[9],[11].

\section{SPECIFICATION}

- Weight: $66 \mathrm{~g}$

- Dimension: 40x20x28 mm approx.

- Stall torque: $17 \mathrm{kgf} \cdot \mathrm{cm}$

- Operating speed: $0.1 \mathrm{~s} / 60$ degree

- Operating voltage: $4.8 \mathrm{~V}(\sim 7.4 \mathrm{~V})$

- Dead band width: $10 \mu \mathrm{s}$

- Motor Type: Coreless

\section{B. Micro Controller}

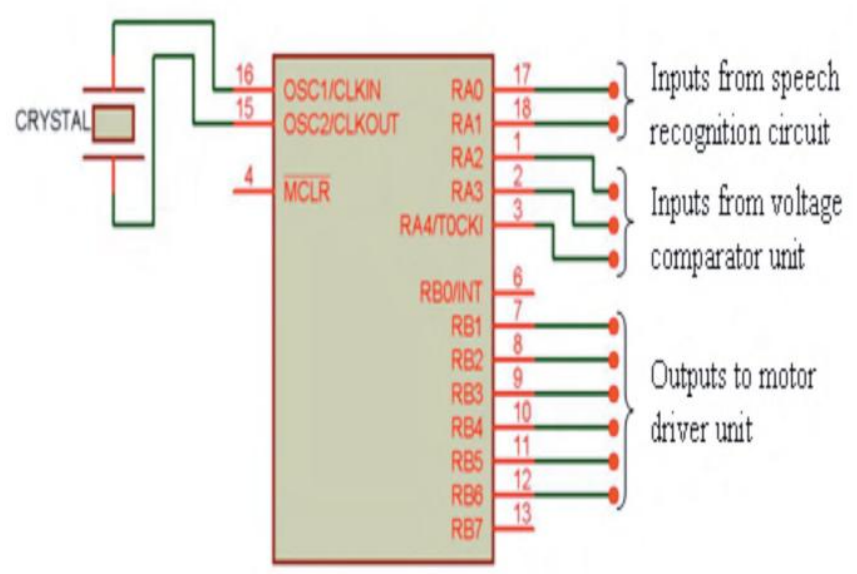

The microcontroller must not work when the discourse acknowledgment circuit produces blunder codes. So as to prohibit these blunder codes from being perceived by the microcontroller, we structured an interface unit. This unit includes 2 rationale entryways, a hook, and a BCD-to-decimal converter. The mix of NAND entryway or potentially door is utilized at the discourse acknowledgment circuit's most critical digit (MSD) yield. The yield of this mix is utilized as ENABLE of the 74LS373 hook. The paired estimations of the discourse acknowledgment circuit's least noteworthy digit (LSD) yield are contributions for a similar lock, as in Figure 10. The double yield is changed over to decimal worth utilizing IC4028. Thus, at whatever point a mistake code is created, the number is disregarded; something else, a decimal estimation of LSD is created as yield.

\section{Speech Recognition Circuit}

The discourse acknowledgment circuit (SRC) is equipped for controlling the prosthetic hand utilizing voice directions (Images SI, Inc., Staten Island, NY, USA). The capacity to speak with a prosthetic hand through discourse is ASYALI,

YILMAZ, TOKMAKC , I, SEDEF, AKSEBZEC 'I, MITTAL: Design and execution of a voice-controlled..., a definitive UI. The client needs negligible experimentation as well as preparing with the prosthetic hand before utilizing it for any reasonable reason.

The fundamental part of the SRC is the HM2007 discourse acknowledgment chip. The HM2007 chip is a CMOS voice acknowledgment chip with voice investigation, acknowledgment procedure, and framework control capacities[8],[10],[12]. The other significant parts are the 64K CMOS Static RAM chip, a mouthpiece, a 12-catch keypad, and a 74LS373 chip, as appeared in Figure 8. Information can be composed and read from the SRAM chip, and the 74LS373 capacities as a lock with 3 -state yields.

\section{Proposed Module}

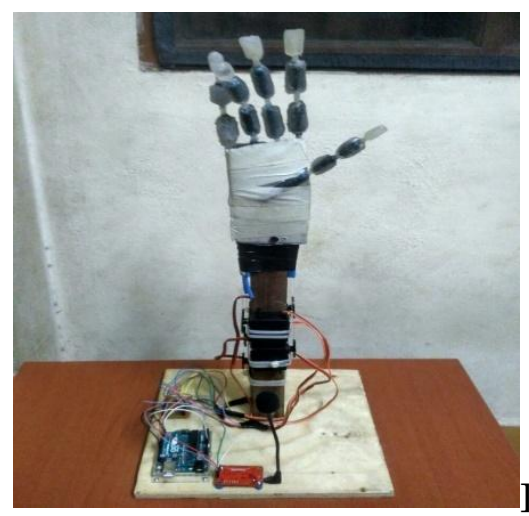

\section{E. Implementation}

The principle objective of our undertaking is to a present Spoken Natural Language interface for Robotics control. We likewise set a few necessities, which are referenced in the Introduction.

- The Spoken Language interface ought to be in English Language [13],[15],[17]

- The robot ought to comprehend the undertaking from the discourse

- The framework ought to be speaker autonomous 
- The robot ought to have some client input, for example, if the robot doesn't comprehend the client directions, it gives the client criticism - "I don't get it".[19],[21],[22]

\section{APPLICATIONS}

- Home Entertainment and Control

- Wireless sensor systems

- Industrial control

- Embedded detecting

- Medical information gathering

- Smoke and interloper cautioning

- Building mechanization

\section{CONCLUSION}

Human-Robot association is a significant, appealing and testing zone in HRI. The Service Robot fame gives the scientist more enthusiasm to work with UI for robots to make it more easy to use to the social setting[14],[16],[18]. Discourse Recognition (SR) innovation offers the scientist the chance to include Natural language (NL) correspondence with robot in characteristic and even way. The working area of the Service Robot is in the general public to help the individuals throughout consistently's life thus it ought to be constrained by the human. In future we have an arrangement to fabricate it economically for humankind. It is useful for the majority of the automated research and venture based work.

\section{REFERENCES}

1. Tatikonda, N.C. \& Naveenchandran, P. 2019, "The behaviour of a compression ignition engine under the influence of diesel and microalgae biodiesel blends", International Journal of Mechanical and Production Engineering Research and Development, vol. 9, no. 4, pp. 447-456.

2. Tatikonda, N.C. \& Naveenchandran, P. 2019, "An experimental assessment on the impact of injection pressure on the characteristics of a diesel engine powered with the blend of diesel and microalgae biodiesel", International Journal of Engineering and Advanced Technology, vol. 8, no. 6, pp. 3284-3291.

3. Karthikeyan, S., Raman Balasubramanian, S.R., Ramesh, B., Raghul, S. \& Sathish Kumar, S. 2019, "The automatic solar tracker chronicles", International Journal of Recent Technology and Engineering, vol. 8, no. 1, pp. 312-315.

4. Hema, R., Sundararajan, M. \& Balaji, S. 2019, "Smartphone control robot with automatic firing gun", International Journal of Innovative Technology and Exploring Engineering, vol. 8, no. 9 Special Issue 3, pp. 625-627.

5. Saritha, B., Chockalingam, M.P. \& Aswathy, M. 2019, "Degradation of anionic dye using Fe/Tio2 composite by photocatalysis", International Journal of Innovative Technology and Exploring Engineering, vol. 8, no. 9 Special Issue 3, pp. 788-791.

6. Saritha, B., Maria Subashini, L. \& Aswathy, M. 2019, "Utilization of spent coffee grounds for compost production", International Journal of Innovative Technology and Exploring Engineering, vol. 8, no. 9 Special Issue 3, pp. 908-910.

7. Fernando, J.K., Meikandaan, T.P. \& Hemapriya, M. 2019, "Better utilisation of bottom ash in coal fired thermal power station", International Journal of Innovative Technology and Exploring Engineering, vol. 8, no. 9 Special Issue 3, pp. 898-900.

8. Kumar, K.S., Kiruthiga, K. \& Thendral, S. 2019, "Experimental analysis on fractional substitution of bond by utilizing rice husk cinder", International Journal of Innovative Technology and Exploring Engineering, vol. 8, no. 9 Special Issue 3, pp. 1163-1165.

9. Vignesh, P., Madan, P., Mohankumar, D. \& Naveenchandran, P. 2019 , "Optimization of four stroke c.i. engine performance by using statistical techniques (mathematical method)", International Journal of Recent Technology and Engineering, vol. 8, no. 2, pp. 1685-1691.

10. Bharanidharan, S., Sathiyamurthy, K. \& Sheeba, B. 2019, "Using co-precipitation method determining synthesis and characterization of fe doped zinc oxide nanoparticles", International Journal of Innovative Technology and Exploring Engineering, vol. 8, no. 9 Special Issue 3, pp. 705-707

11. Jeevanandan, D. \& Vino, J.A. 2019, "Heat recovery from boiler blowdown water by using heat exchanger in thermal power plant", International Journal of Mechanical and Production Engineering Research and Development, vol. 9, no. 3, pp. 219-222.

12. Rakesh, N.L., Balambica, V. \& Kannan, S. 2019, "Biogas extraction from waste orange peel by digestion process", International Journal of Mechanical and Production Engineering Research and Development, vol. 9, no. 3, pp. 323-330.

13. Meenakshi, C.M. \& Krishnamoorthy, A. 2019, "The mechanical characterization of mono and hybrid fiber reinforced composites using experimental and finite element analysis methods", International Journal of Mechanical and Production Engineering Research and Development, vol. 9, no. 3, pp. 189-196.

14. Mohankumar, D., Prem Jayakumar, M., Sabarsish, R. \& Naveen Chandran, P. 2019, "Modeling and experimental investigation on centrifugal blower by computational fluid dynamics", International Journal of Mechanical and Production Engineering Research and Development, vol. 9, no. 3, pp. 331-340.

15. Balambica, V., Deepak, V. \& Kumar, S. 2019, "Design and efficiency of an asymmetric gear", International Journal of Mechanical and Production Engineering Research and Development, vol. 9, no. 3, pp 223-230.

16. Manavalan, S., Balakrishnan, G. \& Ramasubramaniam, S. 2019, "An effect of cobalt oxide nano additive with biodiesel blends using cidi diesel engine", International Journal of Mechanical and Production Engineering Research and Development, vol. 9, no. 3, pp. 211-218.

17. Golden Renjith Nimal, R.J., Sivakumar, M. \& Esakkimuthu, G. 2019, "An investigation on mechanical properties and microstructure of mg/al alloys using $\mathrm{zn}$ interlayer during diffusion bonding", International Journal of Mechanical and Production Engineering Research and Development, vol. 9, no. 3, pp. 125-130.

18. Hariharan, R., Raja, R. \& Vasu, S. 2019, "Mechanical and tribological behaviour of thin tan coating produced on AISI 1018 substrate by DC magnetron sputtering", International Journal of Recent Technology and Engineering, vol. 7, no. 6, pp. 591-598

19. Manavalan, S., Rai, R., Kumar, R.R., Chaudhary, R.K. \& Chaudhary, S.K. 2019, "Impact of modified piston - A review", International Journal of Recent Technology and Engineering, vol. 8, no. 6, pp. 616-620.

20. Manavalan, S., Gopi, A., Arivarasu, J., Abishek Ahi, A. \& Chandru, S. 2019, "Review on ceramic disc brake system", International Journal of Recent Technology and Engineering, vol. 7, no. 6, pp. 612-615.

21. Sabarish, R. \& Jeya Kumar, M.P. 2019, "The design and analysis of piston - Steady state thermal analysis using "ansys"", Internationa Journal of Mechanical and Production Engineering Research and Development, vol. 9, no. 3, pp. 197-204.

22. Ravi, D. 2019, "CFD simulation of solar loading in car", International Journal of Mechanical and Production Engineering Research and Development, vol. 9, no. 3, pp. 231-236. 
Biped Robot: Balance Center of Gravity on Uneven or Smooth Terrain

\section{AUTHORS PROFILE}

R. Hariharan Assistant Professor, Department of Mechanical Engineering, Bharath Institute of Higher Education and Research, Chennai, India.

CM Meenakshi Assistant Professor, Department of Mechanical Engineering, Bharath Institute of Higher Education and Research, Chennai, India.

Durai Raj V P Assistant Professor, Department of Mechanical Engineering, Bharath Institute of Higher Education and Research, Chennai, India. 